\title{
ENTRE LA RUTINA Y LA RUPTURA: EL ARCHIVO COMO ACONTECIMIENTO DE TERRENO
}

\author{
BETWEEN ROUTINE AND RUPTURE: THE ARCHIVE AS FIELD-EVENT
}

\author{
Tristan Platt*
}

\begin{abstract}
Se trata el problema de la caracterización teórica del archivo, y de los usos de archivos de diferentes instancias y tamaños, en el proceso de realizar trabajo etnográfico y etnohistórico. Enfatizando su posición epistemológica entre rutina (cotidiana) y ruptura (epistémica), y a partir del trabajo de varios teóricos de lo archivístico, se examina un archivo indígena que trastorna un concepto de tiempo lineal, y se replantea la relación entre el documento y la memoria.
\end{abstract}

Palabras claves: Archivo, etnografía, etnohistoria, archivo indígena.

The article poses the problem of the theoretical characterization of the archive, and of the uses of archives at different levels and scales, in the process of carryig out ethnographic and ethnohistorical fieldwork. Emphasising the archive's epistemological situation between routine (everyday) and rupture (epistemic), and invoking the work of several scholars of the archival, I examine an indigenous archive which overturns the concept of lineal time, and repose the relation between documents and memory.

Key words: Archive, ethnography, ethnohistory, native file.

Quien alguna vez comenzó a abrir el abanico de la memoria nunca llega al final de sus segmentos. Ninguna imagen le satisface, ya que constató que la memoria puede desplegarse, $y$

que solo en sus pliegues reside la verdad-aquella imagen, aquel sabor, aquel toque, a cuyo propósito todo esto se ha desenvuelto y diseccionado-, y ahora el recuerdo progresa desde el pequeño al más ínfimo detalle y, luego, al infinitesimal, en cambio, lo que se encuentra en estos microcosmos se vuelve siempre más poderoso (Walter Benjamín, en Marx et al., 2007: 49)

\section{Introducción}

Cuando por primera vez hice trabajo de campo, estaba convencido que el conocimiento antropológico podía tan solo producirse mediante la observación participante. Es verdad que me inquietaba una curiosidad (sin duda preantropológica), la pregunta de en qué medida en el siglo veinte podían aún perdurar los descendientes de los tiempos pasados. El proyecto de mi investigación, centrado en la retórica quechua, era un enfoque lingüístico de la toma de decisiones morales y políticas, para ello requería desde luego primero aprender el idioma. Pero mientras seguía los cursos de quechua fui conociendo a un etnohistoriador que llegó a convencerme que no debía abandonar mis primeras inquietudes. Fue así que, cuando ya fui al terreno, recogí textos, hice (y respondí) preguntas, aprendí frases, compilé vocabularios y levanté censos y mapas. Participé en las rutinas productivas y en los calendarios festivos, escuché mitos, realicé entrevistas y participé en sesiones chamánicas. Pude observar hasta qué punto la escritura estaba enmadejada en los actos del habla, grabé fragmentos de los debates, de las memorias y de la historia oral. Pero aún así me encontré conducido inexorablemente hacia el Archivo.

Durante varios años mantuve el terreno y el archivo en un cierto equilibrio, por turnos volviendo a visitar el uno y el otro, como si fuesen dos metodologías dispares, que, empero, en cada acto de escritura tendían a fusionarse en apuntes e imágenes mentalmente asociados. Interrogaba mis notas de terreno desde perspectivas históricas y, a su

* University of St. Andrews, Centre for Amerindian, Latin American and Caribbean Studies (CAS), School of Philosophical Anthropological \& Film Studies. Reino Unido. Correo electrónico: tp@st-andrews.ac.uk 
vez, leía los documentos del archivo a la luz de mis recuerdos de vinculaciones con personas vivas. Se entremezclaban los cuadernos de apuntes del archivo y los del campo con las cintas magnetofónicas, las fotografías y las fotocopias, como si fueran todas huellas complementarias, llegando a constituirse en un holograma de presencias colectivas cambiantes y dilatadas en el tiempo. La gente cruzaba puertas entre segmentos temporales, caminaba a lo largo de varios años agrupados, a veces, hasta volvía a reaparecer en atuendos diferentes, con otro semblante y corte de pelo. Desenmarañar lo que se había fusionado se me presenta ahora como una tarea casi imposible, tanto como reordenar los diferentes estratos según los niveles de memoria que los acompañan. Así y todo, sigo aún hoy, de tiempo en tiempo, soñando en un Archivo total en el que todo vuelve a encontrar su lugar apropiado a fuerza de excavación, ordenamiento y enlace.

Desde luego, un archivo tal como ese sería un ideal, algo imposible en primer lugar y, en segundo lugar, apenas un primer paso. Tendría que crearse un sistema de catálogos transversales y perpendiculares a la estructura arbórea de las secciones, de los legajos y de los expedientes: series artificiales, como las que sugieren algunas tradiciones archivísticas. Estos catálogos vincularían las huellas de específicas poblaciones, lugares y temas, sin estar atadas a un orden original. Tanto como la digitalización de los catálogos, la iniciativa puede exigir la creación de una red de enlaces polisémicos, a la semejanza de una tela de araña, lo que sería un equivalente, para el archivo, de esa nebulosa de pensamiento salvaje que evoca Lévi-Strauss en la "Obertura" de Lo crudo y lo cocido, pero con referencias cruzadas tanto a los acontecimientos históricos como a las mitotemáticas.

El presente capítulo se refiere a la historia y a la antropología, cuyas relaciones podrían imaginarse como el entramado de la vida social. Hay por supuesto otras áreas especializadas de conocimiento en las ciencias humanas y naturales pero todas se arraciman bajo la égida de sociedad e historicidad (Gadamer, [1975] 1980). Aquí me centraré en los procesos de acoger, ordenar y leer huellas materiales que si se las interpreta soltando el vuelo a la imaginación pueden dar impulso a algunas modalidades de comprensión histórica. Seguiré una senda etnográfica en mi acercamiento a los archivos dejando que los archivos me presenten al objeto de mi investigación. Los archivos guardan documentos y declaraciones que registran, en primer lugar, el hecho de su propia inscripción (no siempre están firmados y fechados), y en segundo lugar, referencias a otros sucesos (incluyendo otros documentos) mediante los signos que los constituyen. Doble inscripción, evocada por Paul Ricoeur, que provee los fundamentos para la escritura de archivo, tanto de lo que esté inscrito en el soporte documental como de esas hebras que más tarde entretejerán los historiadores y los antropólogos a variadas distancias de sus fuentes primarias (Sheringham, 2005).

Los archivos nos hablan de diversas maneras, aunque siempre permanecen en los confines de nuestra conciencia. Distingo modos y metáforas del trabajar en los archivos, pero siempre mantengo presentes los mundos que están más allá de los textos. Flotando por encima de la experiencia local, algunos documentos antiguos parecen brillar con mayor intensidad que otros, los más recientes ${ }^{1}$. Pero la investigación de archivo también nos revela senderos más modestos de repetición, desde la iteración de las formalidades diarias procedimentales, las frases notariales y los formateos documentales, hasta la presentación anual de cuentas e informes. Los sistemas de archivos están asociados a la administración de los sucesos de la vida diaria: los seleccionan y agrupan por fechas y temas, los reducen a regularidades por medio de clasificaciones y de la pertenencia a series que confirman el tesón de las rutinas sociales.

Las regularidades se quiebran cuando una importante interrupción (guerras, enfermedades, revoluciones, tsunamis, invasiones) destruye el conocimiento social que produce el archivo. Las disrupciones de la práctica de archivo pueden acompañarse del colapso de un Estado o de la caída de un imperio y también de cualquier interrupción brusca en la continuidad procedimental: algunos archivos han alimentado fogatas para calentar las gélidas noches de los ejércitos. Otros fueron expresamente destruidos para eliminar evidencias acusadoras. Discontinuidades de otro tipo intervienen con las transformaciones en los soportes tecnológicos de la comunicación como, por ejemplo, el desplazamiento del papel, la tinta y estilógrafo hacia el telegrama, el teléfono o el correo electrónico. Son cambios que introducen nuevas rutinas y que dejan otras huellas o quizás ninguna, lo que modifica el tipo de historia que podrá escribirse (cf. Baines, Bennet y Houston, 2010).

Los archivos existen, por ende, entre la rutina y la ruptura. En tanto que rutina, conforman complejas 
jerarquías de oraciones configuradas en moldes temporales que impregnan silenciosamente las vidas sociales de estabilidades y de significaciones. A su vez, esas rutinas cambian gradualmente acompasándose a las largas transformaciones discursivas y tecnológicas. En las páginas siguientes no voy a ofrecer ninguna guía de archivo para investigadores, como las que se pueden encontrar fácilmente disponibles en la Red. ${ }^{2}$ Voy simplemente a alternar algunos recuerdos de mi experiencia en los archivos con unas reflexiones más tentativas acerca de su estatus e implicaciones. En cierto sentido, por sí mismo este ensayo tiene una variedad de posibilidades que constituyen una gama de repliegues, que se espera serán profundizados por los lectores.

\section{Los vivos y los muertos}

Comencemos por el principio, o sea, con el $a{ }^{2}{ }^{3}$. Un sistema de conservación de los registros cotidianos es una herramienta de uso general en la administración estatal y corporativista. Los legajos, como observó Max Weber, son implementos necesarios para toda burocracia moderna. Los armarios de archivo con cajones, inventados en los Estados Unidos de Norteamérica hacia mediados del siglo diecinueve, fueron reemplazando otros medios de conservación de notas, cartas, cuentas, documentos: en anaqueles, apilamientos y atados, mesas, cajones secretos y cajas fuertes, bolsas y décolletés. Los engranajes de la continuidad, eficacia y poderío legal de una institución yacen preservados en cajoneros, primero de madera y ahora de metal, diversificados en una gama de formas y de funciones. Esos recursos fueron complementados por medios digitales de archivar computarizado, hasta tal punto que hay quien piensa que vamos hacia una época liberada del papel (Cook, 1997). Sea como fuere, los sistemas de clasificación que son de uso corriente hoy podrían ser pensados como archivos vivos.

No obstante y hablando en sentido propio, un archivo es el conjunto de documentos y carpetas que han perdurado por ser considerados dignos de ser conservados, aunque ya no corrientes y, por ende y en cierto sentido, despersonalizados y muertos. Pueden ser reubicados en las estanterías del archivo central del Estado o de una organización sea cual fuere, porque la palabra archivo denota a la vez las carpetas conservadas y el edificio en el que son realojadas. Es lo que ocurre con las momias en los sepulcros pintados con rostros que sirven para identificar a la persona y perduran largo tiempo luego de que esta se haya esfumado de la vida cotidiana. Dichos archivos hacen palpables las huellas de un pasado que puede ser reconstituido en tanto evidencia de personas y acciones, ideas y sucesos, cuando interrogados desde un horizonte situado en el presente (Collingwood, 1946; Ginzburg, 1989). Ya desde antes del siglo XVIII, una común característica de los archivos del Estado y de otras administraciones es el aura que proyectan sus augustos edificios y salas de lectura, adornados, como los sepulcros monumentales, de estatuas de ideólogos difuntos y escritores ancestrales. Recintos donde los documentos hablan acallados y son manipulados con aterciopelada destreza, frágiles fetiches que nos colocan en una desasosegante vinculación con el pasado mediante nuevas experiencias táctiles ${ }^{4}$.

Ciertas tendencias recientes han conducido a la desacralización de los archivos. Se los vuelve más accesibles en aras del radio de alcance de los visitantes y debido a las exigencias de los investigadores preocupados por la historia local y familiar. Su apertura también se debe a los vínculos de financiamiento de las fundaciones que tienen una ideología de mercado basada en la racionalidad de los costos-beneficios, el impacto, la afluencia y la cantidad de usuarios. De manera más constructiva, las páginas web son ahora conservadas y archivadas: en el 2010 el Archivo Nacional del Reino Unido sacó copias de las páginas web oficiales del gobierno laborista saliente para conservarlas en línea como un recurso histórico disponible para el gran público ${ }^{5}$.

Las ideas de proveniencia y del orden original indican, en primer lugar, la oficina pública o privada de la que llegan, y en segundo lugar, el orden en el que estaban clasificados antes de llegar al archivo (Roper, 1992). Esto abre una diferencia entre los archivos y las bibliotecas, también respecto de las colecciones de manuscritos que guardan algunas bibliotecas. El único archivo que es necesariamente parte integrante de la Biblioteca Británica es el archivo de su propia administración. Esto, a pesar de que hizo la adquisición de varias colecciones de MSS y, en 1982, obtuvo, como una tarea adicional, la conservación de los legajos de la Administración Colonial de la India ${ }^{6}$. Sin embargo, conceptualmente los archivos son anteriores a las bibliotecas: estas abarcan la variedad infinita del mundo, como en la fantasía de Borges, pero los 
archivos son emblemáticos del conflicto primario entre el orden y el caos.

Ya existían archivos en el mundo antiguo, pero el impulso de la modernidad temprana de centralizar los documentos diplomáticos llegó desde Italia: "Un mundo nuevo de papel había sido engendrado algo así como unos cincuenta años antes del descubrimiento del "Nuevo Mundo"' (Dover 2007)7. En los siglos dieciocho y diecinueve, muchos de los documentos gubernamentales que habían pervivido estaban siendo centralizados, organizados y, a veces, publicados por historiadores. Hacían parte de los esfuerzos de inspirar las nuevas historias nacionales y políticas. El descubrimiento y la clasificación de los archivos trajo una revolución en la tarea de hacer la historia. Se convirtió en la creación de narrativas sólidamente asentadas en fuentes que se proponían exhibir (teleológicamente) la formación de los Estados Nacionales ${ }^{8}$. Al ser parte de este nuevo nacionalismo, los edificios de los archivos se convirtieron en lugares de peregrinaje y en las fuentes oraculares de la verdad patriótica que iba en paralelo a la construcción de otros monumentos históricos (Agulhon, 1981; Nora, [1992] 1996). Los Archives Nationales fueron creados en el París revolucionario en 1790, segundando la instalación del Archivo de Indias en Sevilla (1785). Ambos iniciaron una nueva era en la conservación de documentos públicos, un impulso que, en Francia, se acompañó de quemas intensivas de archivos, cuando los campesinos destruyeron los papeles de la servidumbre (1789). Los nuevos archivos franceses marcaron un momento fundacional, una organización documental que serviría para constituir una nueva conciencia, con un antes y un después centrado en el mito de la Revolución. En la vecina Gran Bretaña, en cambio y por contraste, la Public Record Office fue fundada en 1838 y estuvo destinada a preservar las tramas de una sociedad basada en el mito inverso: la de una monarquía constitucional.

Los archivos coloniales e imperiales tienen, sin duda, un interés peculiar para los antropólogos; a saber, el Archivo General de Indias en Sevilla, los India Office Papers en la British Library, la Bodleian Library of Commonwealth and African Studies ubicada en Rhodes House Oxford, los archivos franceses d'Outremer en Aix-en-Provence y los documentos del Ministerio de las Colonias en Holanda, en el Rijksarchief en La Haya. Habría que añadir, a esta corta enumeración, muchos otros archivos, incluyendo varios empresariales (Business Archives) que contienen información a nivel mundial aunque centrada en el comercio y la economía política de los siglos dieciocho y diecinueve ${ }^{9}$. Todos estos archivos ocupan lugares en una red de archivos que ha extendido su alcance hasta abarcar los archivos postcoloniales y los nuevos archivos nacionales.

Un problema intrincado se presenta aquí, que es la diferencia que media entre un archivo colonial y el archivo de un Estado que intenta incorporar o constituir una nación. Se puede contrastar la exclusión británica de los hindúes subcontinentales luego de la rebelión de 1857, con la Constitución de Cádiz en España que declaró en 1812 (ya demasiado tarde) que todos los indígenas de América bajo dominio de la Corona eran ciudadanos españoles. Fue entonces cuando la investigación etnográfica de la India británica construyó las Castas como un rasgo esencial de la sociedad en la India, que, se daba por establecido, no era abierta hacia la democracia liberal. Pero en España, luego de las rebeliones de los Amarus y los Kataris en 1780-82, y de las explosiones revolucionarias en Norteamérica y Francia, los españoles intensificaron las políticas de hispanización ilustrada, provocando finalmente resistencias antes y después de la Independencia de la parte tanto de los criollos (que sin embargo incorporaron elementos de Cádiz en las primeras constituciones latinoamericanas) como de los indígenas. En cambio, una vez aplastada la gran rebelión de 1857, los británicos orientalizaron y crearon un estado etnográfico, en algo similar al que había existido previamente en los imperios Inca y Español. Estado que -paradójicamente-fue mantenido en los márgenes por las mismas comunidades en la República de Bolivia incluso a comienzos del siglo veintiuno, como veremos ${ }^{10}$.

Los sistemas de clasificación de los documentos no solamente reflejan a las sociedades que los han producido y de cuyas pasadas administraciones conservan huellas. ${ }^{11}$ Más bien, y al contrario, contienen información respecto de las categorías fiscales y administrativas en las que las poblaciones fueron clasificadas y copias de los documentos legislativos con los que esas categorías eran suspendidas o reemplazadas. Las poblaciones pueden ser silenciadas o también se pueden poner palabras en sus labios por medio de un proceso que Andrés Guerrero describe como ventriloquismo. Dicho proceso no funciona tan solo por una traducción del significado sino mediante un proceso de transescritura en el que los escribanos o los notarios transmutan las intenciones de los testigos y los calzan en los catequismos 
sesgados de las cortes de justicia y del Estado. Aún más, hasta se podría afirmar que la estructura y la jerarquía de los archivos llegan a condicionar los tipos de narrativas históricas que pueden llegarse a escribir (Guerrero, 2010).

Sin embargo, diferentes técnicas de lectura, así como la dialéctica entre el orden y el desorden, destapan constelaciones imprevistas en los fondos. Carolyn Steedman nos relata acerca de una referencia biográfica para una sirvienta, la que encontró introducida en medio de legajos ingleses del siglo dieciocho sin ninguna razón ni relación con la mujer (Steedman, 2001). Por igual, la descripción de las vicisitudes de una tripulación a bordo del lugre Moming Star que partió de Ramsgate en una gélida noche de enero de 1846 para rescatar a los marineros del Tesoro de Venecia, un barco austríaco que transportaba carbón de Newcastle a Leghom y que se había encallado en los Goodwin Sands. Cuando pudieron llevarlos al lugre, los tripulantes ingleses del salvavidas ofrecieron café a los marineros austríacos en plena tempestad para que se calentaran. Esta viñeta que hubiera podido inspirar un cuadro de Tumer, o a Dickens una escena dramática, aflora entre áridas cartas dirigidas al barón Rothschild por su agente Thomas Hill, en Southampton, que era el representante del $\mathrm{P} \& \mathrm{O}$, y quien le informaba a Rothschild relativo a los nuevos embarques de mercurio español y cigarros cubanos. Mapas y cuchillos, diagramas y esbozos ${ }^{12}$, o sea, los más insólitos asuntos sin ton ni son brotan de los archivos e impulsan la imaginación del investigador hacia indeterminados cauces.

Al mismo tiempo, respecto del mundo de afuera, que apenas sí los advierte, los archivos moran en una suerte de limbo. Salvo raras ocasiones, quizás tan solo cuando se solicita la copia autentificada de un certificado, la mayoría de la gente apenas sí tendrá un atisbo de las carpetas empolvadas dispuestas en interminables estanterías que sustentan otros atados de inobservados documentos. En los grandes archivos estas filas de estanterías pueden alcanzar la extensión de decenas, cientos y hasta miles de kilómetros ${ }^{13}$, a lo que habría que añadir los sitios Web y $U R L$ que están en una permanente modificación y expansión. Podría parecer paradójico afirmar que los archivos están al margen de una formación social que, sin embargo, muestra signos de su gobernanza. Su extraño poder proviene, sin embargo y precisamente, de esa excentricidad, salvo cuando es exhibido francamente como un kafkiano centro de poder. Los archivos pueden constreñir las afirmaciones que se puede hacer, o sea, los pensamientos que pueden ser pensados en una sociedad según sus diferentes períodos históricos. Foucault los ve como funcionando en los lindes de cada régimen discursivo, empoderando algunos dentro de un orden emergente. Los archivos pueden seleccionar aserciones y performancias que expresan pensamientos y acciones que están más allá de la conciencia advertida de la gente, como algo de la normalidad de lo que la gente da por establecido ${ }^{14}$. De ahí queda apenas un corto paso para concebir los archivos como operando a un nivel subconciente, como algunos sectores de la ley: como plantillas para los pensamientos y las acciones que son aprobadas o reprimidas ${ }^{15}$.

Se encuentran archivos en las sociedades coloniales, nacionales, postcoloniales y regionales. También existieron en los antiguos Estados precoloniales y precapitalistas. No parece que requieran, empero, la existencia de un Estado archivista, tanto como los sistemas de irrigación comunales tampoco exigen un Estado hidráulico (pace Wittfogel ${ }^{16}$. En la edad media tardía, archivos de las comunidades semiautónomas se encontraban en los confines de los reinos europeos y lo mismo sucedía entre los señoríos Aymara-hablantes del sur de los Andes, con sus bultos de cuerdas con nudos o chinu $^{17}$. En cambio, en los Estados sin una escritura glotográfica no forzosamente esto implica una ausencia de archivos. Un ejemplo clásico de una modalidad icónica de conservación de registros es la sofisticada forma de cuerdas y nudos (los khipus) perfeccionados por los Incas; de igual manera, el sistema de conservación en la temprana Mesopotamia en la forma de sellos de arcilla $^{18}$. En realidad, el pensamiento archivístico existe probablemente en todas las sociedades humanas, incluyendo esos pequeños y descentralizados grupos que atesoran piezas inscritas ancestrales, tema al que retomaré.

A nivel doméstico e individual, los archivos de documentos personales se aglutinan en colecciones de objetos que pueden ser estratificados. Derivan los archivos, en efecto, de un deseo estético o existencial de coleccionar y ordenar, tanto como de facilitar la recuperación. Los archivos personales pueden ser distribuidos y rehechos dentro de una dinámica de amistad, prestamo o promoción. Walter Benjamin empujó esta aproximación hasta sus extremos límites. Sus papeles y colecciones fueron muy concienzudamente guardados en sobres, cajas y 
baúles; luego fueron copiados y, por último, repartidos entre sus amistades para conservarlos hasta que reclamara su devolución. Archivó y catalogó las cartas recibidas, los listados de sus lecturas y las anotaciones en papeles cualquiera que pudieran ayudar a situar una idea o una memoria. "Para los recuerdos auténticos", escribió, "resulta mucho menos importante que el investigador informe sobre ellos, es más importante que trace una marca, de manera precisa, del sitio en que obtuvo posesión de los mismos" (Benjamin, en Marx et al, 2007). La alusión es, a la vez, arqueológica y archivística; sin embargo, sugeriré que es engañoso pensar en los archivos como depósitos de memorias.

\section{El archivo de una parcialidad}

Vivía en los Andes cuando decidí visitar nuevamente un archivo. Pero lo que me impulsó no me vino de los cielos nocturnos tachonados de una escritura estelar. Me había estado preguntando referente a cómo el grupo quechua hablante donde vivía podía relacionarse a las sociedades anteriores que habían ocupado los mismos territorios antes y después de la conquista española. La invasión del siglo dieciséis ¿debería conceptualizarse, me preguntaba, como una escena primitiva? o sea, como un momento fundacional traumático de formas posteriores de temporalidad? O, más bien, ¿sería preferible una periodización local, como por ejemplo, la de un antes y después del surgimiento del Sol Inca-cristiano y estatal? La gente me contaba, por lo demás, cómo sus antepasados aymara-hablantes habían transportado y pisado el mineral en las refinerías de Potosí. Algunos hasta representaban memorias ritualizadas de la partida de los trabajadores (los mitayos) desde sus comunidades rurales. Durante uno de esos rituales de partida en 1977, embutidos en el sombrero de un campesino que cabalgaba una mula y al que le llamaban el mitayo, vi pedazos de papel que representaban las escrituras de propiedad de las tierras. Esos papeles eran, según me explicaron, flores ( $t^{\prime} i k a$ ). Rememoraban la tierra comida por los antepasados en los ingenios de beneficio de la plata para poder conservar los derechos de acceso a sus terrenos.

La población había mutado; muchos murieron o migraron. De tiempo en tiempo, algunos españoles y criollos-mestizos se acercaban a los que permanecían y se casaban dentro de esas poblaciones: se convertían en sujetos tributarios. Ya desde antes de la Revolución de 1952 imperaba una opinión generalizada respecto de los radicales bouleversements y el mestizaje, que descartaba toda comparación con las civilizaciones invadidas cuatro siglos antes (Gruzinski, 2000). No obstante, mi estadía en Macha desencapó lo que parecían ser ecos de los tiempos prehispánicos y del temprano período colonial: una división en mitades endógamas, autoridades duales, una organización decimal, patrones de asentamiento vertical, el culto a las montañas, una iconografía geométrica, dualismo tanto social como simbólico, guerra étnica, una geografía sagrada... Estos y otros tropos no podían ser simplistamente descartados como siendo un orientalismo. Por lo demás, voces similares iban surgiendo desde muchas otras sociedades andinas. Solo en los archivos se podía buscar las condiciones de su persistencia y transformación.

De que Macha había sido mencionada desde el momento de la conquista española, me enteré más tarde. Su nombre, entre otros de muchos pueblos y villas, aparecía mencionado como la cabecera de una extensa federación encomendada por Francisco Pizarro a su hermano Gonzalo en 1540. Proviniendo de un archivo-khipu Inca del Cusco, el primer listado en papel se conservaba en el archivo del secretario de Francisco en Lima (Documento 3, en Platt et al. [2006] 2011: 642). Posteriormente apareció un documento en el Archivo General de Indias (Sevilla) que transcribía una temprana tradición oral. Esta se refería a los embajadores despachados por los señores de Macha para parlamentar con el revolucionario Inca Pachacuti, un siglo antes de la llegada de los Pizarro. Si Macha había persistido hasta hoy, ocupando algunas de las mismas tierras y subdivido en los mismos grupos territoriales (o ayllus) que antaño, eso significaba, pensaba, que debieron actualizar sus identidades colectivas mediante adaptaciones sociales sucesivas, a la manera como la memoria renueva creativamente las huellas de experiencias previas ${ }^{19}$. Y cuando los comuneros me advirtieron que los títulos de propiedad estaban en el archivo, su visita se me volvió una urgente necesidad ${ }^{20}$.

Pero, entonces, sucedió algo inesperado: los campesinos de Macha tenían su propio archivo.

El kuraka (jefe de la mitad de arriba, Alasaya) conservaba su archivo junto a un enredo de pedazos de cosas en un cuarto atapialado que servía de bodega. Estaban junto a tejidos cuidadosamente doblados, vestidos tejidos a mano, casacas y pantalones, chalecos bordados, pelotas de hebras y de lana hilada, husos, colorantes químicos; todo eso 
colgado de las vigas y apilado sobre los muebles y en las esquinas del cuarto... Ya no utilizaba los khipus, como lo habían hecho sus antepasados. Tampoco su archivo se guardaba a la usanza española, en una caja de comunidad con tres llaves, como durante el período colonial, sino entre dos pieles secas de cordero, con la lana volteada hacia afuera, atadas con una cuerda de lana trenzada. Pliegos de papel de diferente tamaño estaban colocados a plano entre los dos pedazos de cuero endurecido. Como ya vimos, a los títulos de propiedad, cuando se los invoca en las ceremonias, se los llamaflores ( $t^{\prime} \mathrm{ika}$ ). Podríamos decir, quizás, que esos documentos eran un archivo de flores prensadas...

Los documentos incluían una copia, escrita a máquina del siglo veinte y notariada, de una lista (del siglo XVII) de mojones, de límites colectivos, ubicados por un funcionario español; una testificación (del siglo diecinueve) de los derechos originales de los indios con inscripciones de mojones de los tardíos años 1860 , cuando sus tierras estuvieron amenazadas por un caudillo dictador; certificados de cargos ocupados por los indios tributarios; recibos de las entregas de alimentos efectuadas al ejército boliviano durante la Guerra del Chaco con Paraguay (1932-36); cartas del gobierno revolucionario del MNR convocando a los compañeros campesinos a reuniones políticas; la correspondencia con el Departamento del Tesoro, cuando se hizo entrega del tributo, y los recibos emitidos por el Tesoro; listados modernos de tributarios por comunidad y lugar de residencia.

El viejo kuraka no podía leer los documentos, no obstante, me dijo lo que significaban. Insistió en los documentos de los derechos originales, que los llamaba los kintáli sut'i porque amenazaban con cien latigazos (un quintal de azotes) a quienes vendieran trozos de la tierra comunal. Las órdenes originales eran el fundamento de la posesión colectiva de la tierra: esas tierras habían sido siempre suyas y lo seguirían siendo hasta el próximo juicio (juysyu $)^{21}$. Este documento del siglo diecinueve reorganizaba todos los demás; era como un nuevo arché para la época poscolonial.

Algo había, no obstante, de anacrónico en este archivo de parcialidad. Renovaba un discurso colonial de justicia bajo la República de Bolivia... En efecto, los archivos pueden ofrecer contranarrativas a los discursos que provienen desde la cima del Estado hacia la sociedad abajo; pueden también brindar protección frente a los que están en el poder, incluyendo grupos de ciudadanos blancos excluyentes. Los documentos de Macha defendían un pacto colonial entre el rey y sus vasallos y desafiaban la proclama liberal de que el tributo era un rezago de la tiranía feudal. En verdad, este archivo pertenecía a una dimensión temporal diferente.

Así pues, el archivo reproducía un Estado, pero el Estado apenas si se apercibía de que allí estaba $^{22}$. Tan ignorado como los propios kurakas indios y siendo ambos parte de un controvertido discurso acerca de la autonomía indígena bajo el populismo liberal de la Revolución de 1952. El hijo del kuraka me advirtió que una de las ventajas de una jefatura hereditaria era que ayudaba a que el Archivo permaneciese íntegro. Y es así, por consiguiente, que el Archivo de la parcialidad prolongaba el viejo "pacto"; al sustituir al rey por el Estado republicano, se insistía en abonarle los servicios tributarios como responsabilidad propia de una comunidad territorial de runa bolivianos ${ }^{23}$.

\section{Inscripciones ancestrales}

Como si de un rito de paso a otra disciplina se tratase (a la historia), muchos estudiantes de antropología evitan el trabajo de archivo. La etnografía imagina al campo por afuera o, por lo menos, sobre un terreno, en donde los participantes observadores experimentan la vida cotidiana e intercambian con la gente. El archivo aparta, está enterrado en montones de polvo y de papeles llenos de huellas de muertos ya olvidados. El contraste entre la luz y la vida afuera, y la oscuridad y la muerte adentro, sugiere una platónica oposición entre lo oral claro y definido y la penumbrosa caverna de la opinión inscrita. Dicho contraste reitera un sesgo logocéntrico, por detrás de la inocencia del presentismo romántico del etnógrafo frente a la historia ${ }^{24}$.

Sin embargo la antropología y la historia comparten epistemologías: ambas se sustentan en huellas inscritas de acciones y sucesos del pasado y del presente, complementados por la memoria viva. El trabajo conceptual y creativo viene luego del trabajo de la búsqueda en el archivo. Pero una cosa es teorizar la historia antropológicamente; otra cosa es obligarse al lento trabajo de ir al archivo, solicitar documentos y tomar notas de toneladas de carpetas que, a veces, están en otras lenguas y en caligrafías casi ilegibles, a las que se tiene acceso cumpliendo rituales esotéricos de autopresentación, identificación y pedido que difieren incomprensiblemente de 
un archivo a otro ${ }^{25}$. Análogos rituales intervienen durante la recuperación del material propio de los cuadernos de notas y cajas, archiveros y computadoras del investigador.

Los archivos fascinaban a Lévi-Strauss, aunque su propio proyecto lo condujo por otros caminos. Aseverando que los archivos otorgan una existencia física a la historia al constituir la esencia encarnada del suceso, comparó los documentos escritos a los churinga, esas ancestrales inscripciones en madera o piedra que se conservaban apilados en cavernas de los australianos Aranda. Comparó esas cavernas como sitios de historicidad pura a los edificios de los archivos. Ambos, los churinga y los documentos evidencian una sacralidad que proviene de su significado diacrónico. Lévi-Strauss, empero, argumentó que la temporalidad de los churinga quedaba neutralizada por el pensamiento salvaje, lo que recolocaba esos objetos en el centro de una estructura sincrónica ritual, como una mediación entre los muertos ancestrales y los recientes. Observó también Lévi-Strauss la persistencia de esta manera de pensar salvaje en las sociedades europeas, como ocurre cuando se cumplen las esperanzas de los turistas que visitan las casas de ancestros culturales difuntos. Sus expectativas exigen que haya una cama en la casa de Goethe, aunque a nadie se le ocurre reclamar pruebas de la autenticidad de esa cama: ese requisito es puramente estructural (Lévi- Strauss, ([1962] 2004) ${ }^{26}$.

Esas cavernas y los churinga, Lévi-Strauss los dejó en suspenso, atrapados en los rituales y los procedimientos analíticos para hacer desaparecer el tiempo histórico, recomponiendo el pasado en mito $^{27}$. Existen, sin embargo, opciones alternativas, como, por ejemplo, el orgullo y la reverencia hacia la historia manifestada por los campesinos de los Andes en Rapaz (Perú), cuando contemplan los khipus ancestrales colgados en un archivo templo en la Puna centro-andina ${ }^{28}$. Otro ejemplo es el meticuloso cuidado que las autoridades de Macha prestaban a la conservación de sus flores prensadas. Estos casos nos recuerdan el aislamiento de los churinga aunque también recuerdan a varios archivos ingleses que conservan copias (no certificadas) de la Magna Carta, o aún más, el Arca Hebrea de la Alianza.

Así, más allá de la tensión entre historicidad y las autoimpuestas disciplinas del pensamiento salvaje, el archivo y el terreno podrían considerarse como aspectos complementarios el uno del otro. Frank Salomon elogia a los archivistas rurales andinos como colegas intelectuales, por muy extraña que pueda parecernos la lectura que hacen de los documentos locales (Salomon, 2002). Por consiguiente, el trabajo de archivo puede ser enfocado como trabajo de terreno, tan poético como una lectura mítica de un paisaje cronotópico. Los documentos mencionan los mismos lugares y gentes, como los hallamos en nuestras caóticas notas de terreno, asociándolos a otros todavía no conocidos. Los archivos llegan a ser nexos de sitios múltiples, campos colindantes, regiones o continentes en distintos tiempos, enlaces que son, por lo general, invisibles en el trabajo de campo cuando hecho en un solo lugar. Un archivo conduce a otro y a la presencia de redes de significados sepultados en estratos geológicos por debajo de la superficie. Escarbando en los niveles superpuestos, percibe el etnógrafo el presente como un momento de historia vigente, y el sitio de terreno como un nodo de superficie en una rica fenomenología histórica estratificada ${ }^{29}$.

\section{Narración y verdad}

Son infinitas las voces y las declaraciones que se pueden escuchar en el Archivo Histórico de Potosí, sin embargo no se las puede oír todas a la vez. Cada documento guía por sus propios cauces, introduce a sus propios dramatis personae, impone sus propias circunstancias, manifiesta las condiciones particulares de su producción. Según se procede, las conexiones entre los documentos van asomándose, saltan por la estructura arbórea, van vinculando voces que están delante de uno con voces en otras secciones del archivo. Escuchas asuntos que nunca llegarías a escuchar en el campo afuera, tanto como otros temas que ya has escuchado muy seguido. Quizás, laboriosamente, ya habrás conectado el nombre de un juez, un fiscal, un pequeño abogado o de un Protector de Indios, con otros personajes que aparecen en otros documentos. Esos asuntos ocurrieron sin embargo hace pocos años, o unas décadas, o cuatrocientos años ahí afuera, más allá las paredes del archivo, en el recinto de un juzgado o de una tesorería, una plaza de mercado o una mina de plata, una calle frecuentada o una parroquia rural. El tiempo nuevamente se estira a sí mismo a lo largo de las hileras y hacinamientos de archivos cuyos habitantes se arraciman entre los folios a la espera del tacto de un lector para retomar a una presencia fantasmal, como las secuencias de una vieja película proyectada en nuestras mentes ${ }^{30}$. 
La red intervinculada de archivos, de un Juez de Paz a la Corte Suprema, se asemeja, en ciertos momentos, a algo así como una red de chismorreo, perspectiva que se contrapone a otra perspectiva, un alegato a otro alegato, un testimonio a otro testimonio... ¿Hay un momento de la verdad? Las decisiones acerca de los sucesos son tomadas con las evidencias existentes en la mano y una sentencia puede atribuirse de justa, pero la evidencia puede haber sido forjada, ignorada o descartada ${ }^{31}$. ¿Es procedimental la verdad? ¿Vivimos los sucesos de la manera como los documentos los representan?

Algunos podríamos pretenderlo, como una manera de otorgar sentido a nuestras vidas. Otros podían llegar hasta morir como héroes de sus propias narraciones o de las de alguien más. Pero escuchemos la voz de un historiador de los niños bajo los nazis:

Hay cosas que los novelistas pueden saber respecto de sus personajes, pero no así los historiadores. Los novelistas pueden tener certeza de la lógica emocional que obra en sus personajes, mientras el historiador requiere recordar la apertura de la vida de los protagonistas reales. Al fin y al cabo, los novelistas no requieren probar sus intuiciones contra un aluvión de fuentes incompletas (Stargardt, 2006: 16-17).

Pues como muchas vidas, los archivos permanecen abiertos. Responden a ciertas preguntas pero también formulan otras que quedan sin respuesta, a menos de que se haga un acto de inferencia o de imaginativa re-presentación [re-enactment]. Un nuevo documento puede socavar un encause o conducir a la reescritura de una narración. La apertura, en el sentido de lo no previsible, la confusión y una reescritura permanente, son un hecho constante en las vidas de mucha gente. Visto en este sentido, el archivo puede aproximarse más a la vida que los personajes en una novela y hasta de las narraciones que trazamos luego de doce meses de un autoimpuesto trabajo de campo. Distintas intenciones de diferentes autores, que están presentes en diferentes partes de un documento particular, producen una cacofonía potencial de voces; debemos, por lo tanto, invocar otras nociones de verdad para, así, sopesar el conflicto entre las narraciones.

\section{Metáforas de archivo}

Benjamin escribió, al invitarnos a leer la historia a contrapelo, que cada documento de una civilización lo es también de una barbarie. Una visión distinta, afirmada por Ann Stoler, nos solicita, por el contrario, que leamos el archivo siguiendo el hilo del pelo, tendiendo más bien una relación de empatía con los administradores públicos que escribieron (dictaron) los documentos. Mirados con sus ojos, esos documentos nos revelan las pasiones apenas disimuladas, la decencia, el racismo o la culpa de sus autores, de esa clase media de holandeses coloniales que se traicionan a sí mismos en deslices, sospechas o firmas administrativas. Stoler (2009) nos expone su lectura institucional de un gran archivo, el Rijksarchief de La Haya, como una condición previa a otros tipos de lecturas, y caracteriza su enfoque como etnográfico al mismo tiempo que empuja hacia un margen los esfuerzos de trabajar a contrahilo como si fuesen una mera minería o extracción ${ }^{32}$.

Una falsa antinomia está planteada aquí, pues las minas han permitido etnografías de la mejor calidad. ${ }^{33}$ Gunnar Mendoza, quien fue director del Archivo Nacional de Bolivia, utilizó la metáfora extractiva cuando ayudaba a los investigadores a encontrar guías que respondieran o diversificaran sus intereses. Sabía que todo el Archivo y, aún más, todo el sistema de archivos, estaba más allá de la capacidad, del alcance de una persona por sí sola, sea cual fuere la dirección del hilo de su lectura. Entonces, presentaba al Archivo Nacional como una mina donde se sigue algunas vetas hasta que se desbordan o dispersan, mientras otras pueden abrirse. Creaba instrumentos de investigación, series artificiales en tarjetas de archivero por tema (trabajo minero, trabajo indígena, rebeliones, etc.) perpendiculares al orden original de los documentos. La metáfora geológica brota nuevamente. Las guías podían seguirse de una sección o serie a otra, de un archivo al siguiente, tal como un filón puede correr por debajo de varías minas; lo que nos aporta otro atisbo de un archivo total. No vale menos la imagen de la extracción documental, organizada trabajando diferentes vetas en repositorios distintos y utilizando instrumentos de investigación que cruzan transversalmente la organización del archivo, que las entrevistas hechas a los ingenieros en una sola mina a cielo abierto quienes, por lo general, marginan a los trabajadores, sus diablos y sus muertos. Las pepitas etnográficas se descubren solo a aquellos que se escarban; es así, como mineros, que descubrimos las voces de los marineros del bote salvavidas de Ramsgate en la temprana época victoriana ${ }^{34}$. 
A un nivel más profundo, los archivos nacionales de los países poscoloniales se sustentan en los archivos coloniales que precedieron a la nación; a su vez, secciones de los archivos hispanoamericanos coloniales se sustentan en los archivos perdidos Inca o Nahua; y, también, en las cavernas o las colecciones de khipu de grupos sociales precedentes o contemporáneos. Los archivos coloniales están asociados con Cusco o Tenochtitlan, así como con los virreinatos de España en Lima, Buenos Aires, Santa Fe o México. Y también, a otro nivel, con los archivos de la Corona y el Consejo de Indias que ahora se guardan en la vieja Casa de los Contratos de Felipe II en Sevilla. Cada gran depósito colonial articula grupos de archivos menores que se diseminan hacia abajo en las colonias de los virreinatos y cortes de justicia a los Comisionados de Distrito, los Oficiales de Campo, o los Corregidores de Indios. A medida que se alejan cada vez más de la metrópolis, ocurre un cambio radical pues entran en contacto con condiciones sociales muy diferentes de aquellas donde sus principios fueron pensados. En respuesta a nuevas situaciones como las Independencias nacionales, cortos de material y dependientes de su ingenio, los archivistas emergentes nacionales, regionales y locales se inventan sus propias maneras de hacer las cosas (Lovering, 2010).

\section{Un archivo nacional}

Fue en agosto de 1971 cuando bajé de la Puna, cruzando montañas tapizadas de maíz, hacia Sucre, la ciudad colonial y del diecinueve, sede de la Corte Suprema y capital de Charcas y de Bolivia. Atravecé una plaza umbrosa con, en su centro, la estatua del presidente Antonio de Sucre. Niños jugaban en los dos leones situados al pie del monumento. A lo largo de la calle España, una media cuadra más abajo, se llegaba a la sede del Archivo Nacional de Boliva (ya reemplazado por un nuevo edificio ubicado detrás del Palacio Prefectural). Dos descansos más arriba de una crujiente escalera de pulidos escalones de madera con un olor impregnante a cera, me encontré en un cuarto con libros alineados en sus paredes, y ventanas que miraban hacia la calle. En una silenciosa y disciplinada atmósfera se atareaban equipos de trabajo en sus máquinas de escribir. En una de las esquinas, un hombre pequeño, con actitud alerta y mirada que abarcaba todo, estaba sentado en un escritorio encerado.
Una de las tareas de don Gunnar era atender a las autoridades indígenas que venían a Sucre en búsqueda de los títulos coloniales de sus tierras originarias. Llegaban silenciosos, subían por los crujientes escalones vestidos de sus ponchos característicos, sus sombreros y sandalias, y en la mano varas de mando negras con anillos de plata. Se sentaban frente al Director que les hablaba en quechua y les guiaba hasta que encontraran los papeles que buscaban. Luego les entregaba fotocopias. Esa tarea le provocaba a don Gunnar una particular satisfacción. Los visitantes, con incredulidad ante la cortesía con la que se les recibía, sonreían y le agradecían.

Me presenté y registré, hablé de mis inquietudes, y él puso ante mí una Guía de Investigadores y uno de los catálogos que había compilado. Era un catálogo burdo, una cajonera hecha en casa reforzada con un papel engomado de color marrón, las fichas habían sido trabajosamente recortadas a la tijera. Cada una exhibía el título y el número de un documento colonial relativo a "Tierras de indios" escritos a máquina y corregido a lápiz. Muchos catálogos en papel son provisionales y se los actualiza constantemente con anotaciones marginales. Hoy en cambio, los archivos informatizados me provocan la impresión de una decepcionante e inmaculada finalidad.

Entre las tarjetas había una referencia a Documentos coloniales del año 1579, $n^{\circ} 46$. "Los Indios de Macha contra Alonso Díaz por las tierras de Uru y Carasi". Me fue traído de su caja y estantería por un trabajador del archivo y resultó ser un documento deteriorado con más de 150 folios, cada uno escrito por recto y verso con una caligrafía de variada calidad de legibilidad. Su deterioro se concentraba en un pequeño agujero de vieja humedad que se iba ampliando conforme se avanzaba hacia las últimas páginas. Ya en las últimas páginas, cuando la caligrafía se volvía más ardua para descifrar, y los folios eran jirones, tuve que escarbar pepitas en frágiles retazos de papel; el documento ha sido ahora escaneado y lo hemos publicado.

Aún así, me quedaba suficiente para encontrar una referencia a las dos parcialidades de Macha, sus diez ayllus y los pisos de tierras verticales que se extendían desde la puna hacia abajo, a los valles maiceros donde yo había estado viviendo, y, río abajo, a los campos irrigados de ají, zapallo y algodón en Carasi. A un español de nombre Alonso Díaz se le había otorgado una merced de tierras en 
1579 por orden de la Audiencia de La Plata, como se llamaba entonces Sucre. Tenía un contrato para abastecer a los mineros de Potosí de madera traída de esos valles. Había intentado ampliar la concesión de tierras hasta abarcar los campos de cultivo macha. Entonces, los macha bajaron y expulsaron el ganado de Díaz de sus cultivos, mientras este cargaba al galope contra ellos asestándoles sablazos. Esos fértiles y calientes valles fueron el objeto de un litigio en el que el Protector de Indios Joan de Baños hizo de las suyas. El conflicto dejó huellas de la violencia cotidiana que conlleva la formación de una economía global, confirmando, al mismo tiempo, un patrón de asentamiento preeuropeo que aún persiste hoy en muchos valles surandinos ${ }^{35}$.

\section{Acontecimientos}

Una de las razones por las cuales no se puede afirmar que un ordenador tenga memoria es que la memoria, contrapuesta a la memorización, es creativa; la imaginación de manera permanente remodela los sucesos pasados en el proceso de recordar. El objetivo del ordenador es conservar $\mathrm{y}$, por otra parte, buscar textos tal como fueron guardados. Le falta imaginación al ordenador, y un inconsciente. Retienen objetos de tal manera que puedan ser recuperados tal cuales. Re-memorar el pasado de manera que siempre emerjan diferentes pasados, aunque conectados entre sí, variando según la cantidad y cambios en las perspectivas, es un acto de incardinada creatividad que, afortunadamente, está más allá de las posibilidades de un ordenador ${ }^{36}$.

¿Y los archivos? ¿Serán casas de la memoria donde siguen titilando las historias y los sucesos que han sido olvidados afuera? Los archivistas están enamorados de la metáfora, lo que significa que se pretenden los guardianes de la memoria (v.g. de la nación). Como argumenta Steedman (2001: 68), sin embargo, "en los archivos verdaderos, a pesar de que pueden haber montañas de fajos, en realidad, no hay mucho en ellos. El archivo no está constituido de cualquier cosa, como lo está la memoria humana. Son solo unos fragmentos que sobreviven". Visto desde otro ángulo, Yerushalmi (1996-97) escribe: "La memoria no es un archivo, tampoco un archivo es un banco de la memoria. Los documentos de un archivo no son parte de una memoria, si lo fueran, no necesitaríamos recuperarlos. Cuando se los recupera, por lo general están en discordancia con la memoria". Pues, estos fragmentos pueden servir para corregir a una memoria que ha reescrito el pasado, un control que solo es posible cuando las memorias vivas son reemplazadas por sistemas gráficos y estanterías, polvo y carpetas y ahora ordenadores ${ }^{37}$.

Y así se nos presenta el problema de la amnesia histórica, la represión y el ocultamiento. Los archivos cerrados pueden abrirse a la luz como, por ejemplo, con la reciente difusión de los expedientes secretos del Departamento de Estado norteamericano, y muchos otros, por Wikileaks. En la Mongolia de hoy Chris Kaplonski (2010) exploró el uso de los documentos que rehabilitaban a las víctimas de la represión de los años mil novecientos treinta en provecho de sus descendientes. Los archivos que están en dominio público son ampliamente sobrepasados por lo que está escondido, lo cual gobierna el mundo sin que caigamos en cuenta y silencia la evidencia exigida por las verdades impugnadas. Su divulgación paulatina pone de manifiesto los mecanismos del poder y, aún aquí, sin embargo, no hay mucho alli ${ }^{38}$.

¿Cómo podríamos expresar la relación entre esos retazos y nuestra imaginación? Todo archivo tiene su propia rutina para suministrar a los investigadores de ficheros. Actualmente en el Archivo General de Sevilla pides los documentos no escaneados desde el mismo ordenador que se le asigna a cada investigador. Esperas diez minutos o media hora, entonces te diriges hacia la mesa de recepción. “¿Ya llegó Charcas 16? "Todavía no” A la espera, te pones a explorar documentos escaneados en la pantalla o si no bajas las escaleras a tomar un café en el bar que está al lado del Archivo y, en el camino, chismorreas con los colegas. Regresas, pasas el control de seguridad y trepas apurado las gradas de mármol. Siguen sin noticias. Finalmente llega un carrito, trae una carpeta gorda a reventar, cuyo contenido desborda y apenas si se sostiene entre las tapas atadas con dos cuerdas y un lazo... Firmas la entrega y te la llevas a tu mesa. Delicadamente desatas las cuerdas, pones de costado las tapas y abres la carátula: descubres un montón de papeles atados con unos frágiles lazos de algodón. También los desatas, retiras una hoja en blanco y, entonces, contemplas la pila de documentos tal cual (Georges Lefevre escribió acerca del placer que sentía cuando desataba los lazos en el ático de la mairie donde trabajaba).

Al fin puedes abrir cada documento y escanear cada página, alisando bien el papel a ras con la mano, 
sin detenerte cuando es un documento que no capta tu atención, con mucho más cuidado cuando si la retiene. Volteas las hojas según avanzas, cara hacia abajo, al costado de la primera: la primera pila se va achicando. Trabajas con los informes del siglo dieciséis del Presidente de la Audiencia de Charcas dirigidos al rey y el Consejo en la lejana Madrid. Hojeas los párrafos de pulcra escritura, buscas una palabra clave, un topónimo que te sea familiar, quizás el nombre de una persona... Vas siguiendo una campaña contra los indios Chiriwana, los descubrimientos de recientes minas, los movimientos de los portugueses, la muerte por garrote de un intérprete corrupto, el regreso a las costas del Pacífico del corsario inglés Drake; la seguridad del reino, la expansión de la frontera minera, un escándalo gubernamental, los movimientos del enemigo; los boletines noticieros más recientes para ese año, mes y día. Cada palabra tiene aquí importancia. Un río, una montaña, un puesto, una fecha, un capitán, un verbo, son suficientes como para urdir un movimiento, percibir un enfrentamiento, zanjar un suceso. Indicios con los que se puede arriesgar una tendencia o una táctica; quizás hasta adelantar una respuesta.

El catálogo de la sección Charcas ${ }^{39}$ le desliza al investigador, sin que repare, a detalles recónditos y siempre más poderosos, escondidos en un archivo muerto de retazos y vestigios. Pero estos difieren radicalmente de los abanicos de Benjamin que despiertan las neuronas carnosas de la imaginación, en donde se gestan nuestras re-memorizaciones creativas de las cosas pasadas.

\section{A modo de conclusión}

Retomando al arché: dos consecuencias enmarcan el conflicto del acceso. En cuanto a la primera, el procesamiento de las series y la selección que se hace para archivarlas se vuelve una reiterativa función que fija una rutina llana. Feldman en su trabajo acerca de la burocracia en Gaza bajo los mandatos británico y egipcio, señala la importancia que tuvieron los archivos para mantener una administración básica que reproducía un país sin Estado. Los archivos tanto los vivos como los muertos, en este caso, guardan huellas de las decisiones y sucesos diarios (impuestos, distribución de leche, mercados) condensados en un murmullo de negocios en permanente vibración, un Chaoskampf de archivo a ras del suelo que, hoy, todavía intenta compensar el alboroto ${ }^{40}$.
La segunda consecuencia es la caída en el caos cuando ocurre la ruptura de una continuidad burocrática acarreada por un colapso de la sociedad, la marginalización o una revolución. El cese del proceso de seleccionar para la conservación significa el cese de los grandes archivos y de sus hacedores. Una imagen de la Temprana Edad Media cuenta el colapso de los archivos romanos en Europa occidental cuando fueron reducidos a unos pocos monasterios, candiles en la oscuridad, aunque floreció ampliamente el arte de la memorización. No obstante, los métodos de los archivos pueden reinventarse, o acuñarse nuevos: son los componentes de un reinventarse de la sabiduría de gobierno entre los condados y los estados medievales. Así, los archivos chinos bajo la dinastía de los Ming fueron repartidos por varias islas en un lago para protegerlos del fuego, pero sucumbieron finalmente en una conflagración dinástica. En ambos casos el conocimiento archivístico (tanto como la escritura) fue nuevamente recuperado. En realidad, estas técnicas utilizadas para reproducir rutinas pueden a veces sobrevivir al impacto de revoluciones políticas y mantener profundas continuidades por detrás de las apariencias de un cambio radical.

Hoy el poder político está siendo impugnado por la vía de conflictos respecto de la creación, preservación y destrucción de archivos electrónicos para los que la prohibición y el acceso están reglamentados por legislación y candados electrónicos, por decisiones ya sean individuales o colectivas; y, sobre todo, están regulados por medio de los canales de las contiendas cibernéticas entre hackers y Estados, corporaciones e individuos. Esas confrontaciones evocan pesadillas en las que, luego de la ruptura, pequeños grupos de fantasmas se apiñan entre las ruinas laberínticas de archivos virtuales en descomposición. Mientras tanto, la visión kafkiana, ahora abiertamente instalada en todas las pantallas, encierra cada vez más a los que atrapa en el laberinto virtual de los sitios-web corporativos, cuyas ramificaciones pueden parecerse, no tanto a una nebulosa, o a catálogos, o aun a corredores, sino más bien a trampas hechas de algodón de azúcar y tejidas a propósito con silicón y tungsteno.

De todas maneras, las rutinas de los sobrevivientes, como también de los hackers, remontan sus huellas hacia las formas elementales del pensamiento archivístico, a las cavernas llenas de churinga de 
los Aranda, a las cápsulas temporales apiladas de Warhol o de Roland Barthes ${ }^{41} \mathrm{o}$, tal vez aun, a los poderosos microcosmos de W. Benjamin. Estas formas podrían expresarse en una disposición de colecciones de objetos: parafernalia sagrada, pero también piedras, flores, tejidos, nudos, papeles, cajas, abanicos, monedas... los objetos a los que prestamos devoción y que, como si fueran conchas tropicales de la memoria, cuando se las acerca al oído, transmiten el eco del rugido y de la música de un océano lejano ${ }^{42}$.

\section{Agradecimientos}

Quiero agradecer a Olivia Harris por su invitación a escribir este trabajo poco antes de su extemporánea muerte en abril del 2009, y a Andrés Guerrero por su traducción.

\section{Referencias Citadas}

Abercrombie, Tilomas

1998 Pathways of Memory and Power, Wisconsin University Press, Madison.

Absi, Pascale

2003 Les Ministres du Diable, L'Harmattan, París.

Agulhon, Mauricem

1981 Maríanne into Battle. Republican Imagery and Symbolism in France, 1789-1880, Cambridge University Press, Cambridge.

Axel, Brian Keitfa

2002 "Introducción", en From the Margins: Historical Anthropology and its Futures, Duke University Press, Durham y London.

Baines, John; Bennet, John y Houston, Stephen (editores) 2010 The Disappearance of Writing Systems, Perspectives of Literacy and Communication, Equinox Publishing, London 2010.

Burger, Richard

2000 Chavin: The Origins of the Andean State, Thames y Huston, London.

Burke, Peter

2007 “Commentary”, Archival Science, núm. 7 pp. 391-397.

Collingwood, Robin

1946 The Idea of History. Oxford University Press, Oxford.

Collingwood, Robin

2005 The Philosophy of Enchantment. Studies in Folklore, Cultural Criticism and Anthropology. Edición por Boucher David, James Wendy, y Smallwood, Philip. Oxford University Press, Oxford.

Cook, Terry

1997 "What is Past is Prologue: A History of Archival Ideas Since 1898, and the Future Paradigm Shift", en Archivaria 47, [en linea] http://www.mybestdocs.com/cook-t-pastprologue-ar43fnl.htm

Damerow, Peter

1999 "The Origins of Writing as a Problem in Historical Epistemology", Max Planck Institute for the Histoiy of Science, [en línea] http://www.mpiwg-berlin.mpg.de/ Preprints/P114.PDF

Das, Veena y Poole, Deborah (editores)

2004 Anthropology in the Margins of the State, School of American Research, Santa Fé.

Demelas, Marie-Danièle

1992 L'invention politique. Bolivie, Equateur, Pérou au XIXéme siécle, Recherche sur les Civilisations, París.

Derrida, Jacques

[1995] 1996 Archive Fever. A Freudian Impression, The University of Chicago Press, Chicago y Londres.
Dover, Paul Marcus

2007 "Deciphering the Diplomatic Archives of Fifteenthcentury Italy”, Archival Science núm. 7 pp. 297-316.

Farge, Arlette

1989 Le Goút d'Archive, Seuil, París.

Feldman, Ilana

2008 Governing Gaza. Bureaucracy, Authority, and the Work of Rule, 1917- 1969, Duke University Press, Durham y London.

Foucault, Michel

[1969] 1970 La arqueología del saber, Siglo XXI, México.

Fox, Adam

2000 Oral and Literate Culture in England, 1500-1700, Oxford University Press, Oxford.

Gadamer, Hans-Georg

[1975] 1980) Truth and Method, Continuum Publishing, London.

Ginzburg, Cario

1989 Clues, Myths and the Historical Method, Johns Hopkins University Press, Baltimore.

Gouda, Francés; Raben, Remco; Schulte Nordholt, Henk y

Stoler, Ann Laura

2009 "Debate Ann Laura Stoler", en Bijdragen Tot de TaalLand- en Volkenkunde, Vol. 165, núm. 4, pp. 551-567.

Grafton, Anthony

1999 The Footnote. A Curious History, Harvard University Press, Cambridge.

Gruzinski, Serge

2000 El pensamiento mestizo, Paidós Ibérica, Barcelona.

Guerrero, Andrés

2010 Administración de poblaciones, ventriloquia, y transescritura, Flacso Sede Ecuador-Instituto de Estudios Peruanos, Lima.

Halbwachs, Maurice

1992 On Collective Memory, University of Chicago Press, Chicago.

Harris, Olivia

1987 "De la fin du monde: Notes depuis le Nord-Potosî”, en Cahiers des Amériques Latines 6, número especial Bolivie: fascination du temps et organisation de l'apparence, editado por Thérése Bouysse, pp. 93-118.

Kaplonski, Chris

2010 “The Many Lives of Secret Police Files: Repression, Rehabilitation and the Hermeneutics of Documents in Mongolia", Ponencia presentada al Taller sobre State Archives and State Repression in Socialist Mongolia, Cambridge. 
Lévi-Strauss, Claude

[1962] 2004 "Time regained", The Savage Mind, Weidenfeld and Nicholson,, London.

Lovering, Timothy John

2010 "British Colonial Administrations' Registiy Systems: a Comparative Study of Northern Rhodesia and Nyasaland", Archival Science, núm 10, pp. 1-23.

Marx, Ursula; Schwarz, Gudrun; Schwarz, Michael y Wizisla, Erdmut (editores)

2007 Walter Benjamin's Archive: Images, Texts, Signs. Verso, Londres.

Mazikana, Peter

1990 Archives and Records Management for Decisión Makers: a RAMP Study, UNESCO, París, [en línea] Htpp://www. unesco.org/webworld/ramp/html/r9008e00.htm\#Contents

Menegus Bornemann, Margarita

1999 “Los títulos primordiales de los Pueblos de Indios", en Menegus Bornemann, Margarita -editora- Dos Décadas de investigación en historia econónomica en América Latina. Homenaje a Carlos Sempat Assadourian. El Colegio de México, México.

Moore, Sally Falk

1987 "Explaining the Present: Theoretical Dilemmas in Processual Ethnography”, American Ethnologist, Vol. 14, núm. 4, pp. 727-736.

Nora, Piene

[1992] 1996 Realms of Memory. Rethinking the French Past. Columbia University Press, New York.

Platt, Tristan; Bouysse-Cassagne, Thérése; Harris,Olivia

20062011 Qaraqara-Charka. Mallku, Inka y Rey en la Provincia de Charcas. Institut Français d'Études Andines / Plural Editores / University of St Andrews / University of London, La Paz.

Platt, Tristan y Quisbert, Pablo

2007 "Knowing Silence and Merging Horizons: The Case of the Great Potosí Cover-up", en Harris, Mark -editorWays of Knowing. New Approaches in the Anthropology of Knowledge and Learning, Berghahn, Oxford.

Quilter, Jeffrey y Urton, Gary (editores)

2002 Narrative Threads: Accounting and Recounting in Andean Khipu. Texas University Press, Austin.
Roper, Michael

1992 "The Development of the Principies of Provenance and Respect for Original Order in the Public Record Office" en Craig, Barbara - editora- The Archival Imagination: Essays in Honour of Hugh A. Taylor, Association of Canadian Archivists, Ottawa.

Salomon, Frank

2002 "Unethnic Ethnohistory: on Peruvian Peasant Historiography and Ideas of Autochthony”, en Ethnohistory, Vol. 49, núm. 3, pp. 475-506.

Salomon, Frank

2004 The Cord-Keepers. Khipus and Cultural Life in an Andean Village, Duke University Press, Durham.

Sheringham, Michael

2005 "Memory and the Archive in Contemporary LifeWriting", en French Studies, Vol. LXI, núm 1 pp. 47-53.

Stargardt, Nicholas

2006 Witnesses of War. Children's Lives under the Nazis. Pimlico, London.

Steedman, Carolyn

2001 Dust, Manchester University Press, Manchester.

Stoler, Ann Laura

2009 Along the Archival Grain, Epistemic Anxieties and Colonial Common Sense, Princeton University Press, Princeton.

Strachey, James (editor)

1940 International Journal of Psycho-Analysis 21, Institute of Psycho- analysis, Bailliére, Tindall.

Taylor, Anne-Christine

2007 "Sick of History: Contrasting Régimes of Historicity in the Upper Amazon", en Fausto, Carlos y Heckenberger, Michael, Time and Memory in Indigenous Amazonia. University of Florida Press, Gainesville.

Urton, Gary

2003 Signs of the Inca Khipu: Binary Coding in the Andean Knotted String Record. Texas University Press, Austin.

White, Hayden

1975 Metahistory. The Historical Imagination in Nineteenth Century Europe, Johns Hopkins University Press, Baltimore. Yerushalmi, Yosef Hayim

1996-97 "Series Z: An Archival Fantasy", en European Journal of Psychoanalysis, núm. 3-4, [en línea] http://www. psychomedia.it/jep/number3-4/yerushalmi.htm

\section{Notas}

1 La metáfora astronómica proviene de Michel Foucault (1970 [1969]): "El archivo es en primer lugar la ley de lo que puede ser dicho, el sistema que rige la aparición de los enunciados como acontecimientos singulares. Pero el archivo es también lo que hace que todas esas cosas dichas no se amontonen indefinidamente en una multitud amorfa, ni se inscriban tampoco en una linealidad sin ruptura, y no desaparezcan al azar solo de accidentes externos: sino que se agrupen en figuras distintas, se compongan las unas con las otras según relaciones múltiples, se mantengan o se esfumen según regularidades específicas: lo cual hace que no retrocedan al mismo paso que el tiempo, sino que unas que brillan con gran intensidad como estrellas cercanas, nos vienen de hecho de muy lejos, en tanto que otras, contemporáneas, son ya de una extremada palidez".
2 Para los archivos en el Reino Unido, ver http//archiveshub. ac.uk/. Para una introducción general: Mazikana (1990).

3 El doble significado de arché, comienzo y orden, el principio ontológico y el nomológico, es la preocupación de las páginas iniciales de Jacques Derrida ([1995] 1996).

4 Jules Michelet sentía intensas sensaciones de comunión con los muertos antes de hacerlos resucitar en sus escritos (White, 1975; Steedman, 2001).

5 Ver http://www.nationalarchives.gov.uk/Avebarchive/

6 http://www.bl.uk/reshelp/findhelpregion/asia/india/indiaofficerecords/indiaofficehub.html

7 La centralización de los documentos se llevó a cabo por Elisabet I en Inglaterra, Colbert en Francia y, en España, por Felipe II.

8 Como en la metodología rankeana. La nota de pie de página aparece junto al archivo moderno, dando acceso a 
las fuentes primarias como evidencias para las afirmaciones del historiador (ver Grafton, 1999; cf. Axel, 2002).

9 Por ejemplo los Rothschild Archives London en: http:// www.rothschildarchive.org/ta/, o los Jardine, Matheson Archive en: http://janus.lib.cam.ac.uk/db/node.xsp?id=EAD/ GBR/0012/MS\%20JM

10 Respecto de la Constitución de Cádiz de 1812 que permitió que los indígenas andinos y mexicanos votaran en las elecciones municipales, véase Demelas (1992).

11 Las inquietudes de Peter Burke (2007: 395) en sus Comentarios cuestionan si la organización de clasificación realmente debe verse como un "reflejo" de las relaciones de gobierno.

12 Archivo Rothschild Londres, Correspondencia Sundry, XVI/19/8A(1846). Esta serie de documentos está organizada de manera alfabética por año: este documento aparece bajo "H" para 1846. Va acompañado por una nota adjunta escrita por Edward Hodges a Lionel de Rothschild, Cónsul de Austria en Londres, pidiéndole ayuda para los marineros.

13 Los Archivos Nacionales de Francia comprenden casi 3.000 $\mathrm{km}$ de anaqueles, entre documentos nacionales $(367 \mathrm{~km})$, departamentales $(2.11 \mathrm{~km})$ y comunales $(441 \mathrm{~km})$. Ver: "Chififres-clefs 2005", en http://www.archivesnationales. culture.gouv.fr/

14 En español antiguo por ejemplo, amor (del soberano) se contraponía a libertad (desobediencia, subversión). La antinomia libertad/esclavitud se había vuelto dominante solo hacia 1800 , expresando el deslizamiento hacia un régimen discursivo liberal y el impacto que tuvo la Revolución Negra en Haití.

15 Sugiere Jacques Derrida (1996 [1995]) que el inconsciente trabaja como un archivo en el que una infinidad de impresiones de la memoria individual son conservadas y hablan en despropósitos. La palabra "archivo" es rara vez utilizada por Freud, por lo tanto, los textos claves que utiliza Derrida son "Delusion and dreams in Jensen's Gradiva" (1909) y "A Note upon the "Mystic Writing Pad" (1925) (Strachey 1940). Aquí se trata de una comparación de las inscripciones de huellas en la cera con las imágenes en capas superpuestas que forman un palimpsesto en el inconsciente, tal como se encuentra en algunos documentos de archivo.

16 Respecto de las comunidades hidráulicas, para los Andes, véase la crítica de Richard Burger (2000) a Wittfogel en Chavin: The Origins of the Andean State.

17 En cuanto a la interacción entre memoria y archivo en la Inglaterra medieval y los tempranas comunidades modernas, véase Adam Fox (2000) Oral and Literate Culture in England, 1500-1700. En cuanto a la combinación de memoria con el registro en las cuerdas andinas anudadas, ver Jefrey Quilter y Gary Urton (2002) Narrative Threads: Accounting and Recounting in Andean Khipu. Chinu (Aymara) $=k h i p u$ (Quechua).

18 El Estado Inca no utilizó la logografía pero en cambio sí tenía un elaborado sistema de archivos, ver Gary Urton (2003) Signs of the Inca Khipu: Binary Codmg in the Andean Knotted String Record. Ver por igual Harvard University's Khipu Database Project en: http://khipukamayuq.fas.harvard. edu/ WhatIsAKhipu.html. En cuanto a los archivos antes de la escritura: Enrica Fiadra y Piera Feroli, "The Use of Clay Sealings in Administrative Functions from the Fifth to First Millennium BC, in the Orient, Nubia, Egypt and the Aegean: Similarities and Differences", disponible online en: http:// www2.ulg. ac.be/archgrec/lMG/aegeum/Aegaeum5(pdf)/ Fiandra.pdf. La autonomía de esos sistemas de registro, contrariamente a su conceptualización como defectuosas formas de escritura protologográfica, es argumentada para la Mesopotamia por Peter Damerow (1999), citado en Salomon (2004).

19 El acceso a las ecologías verticales en el siglo veinte tardío destaca notables microcontinuidades con la situación en el temprano siglo diecisiete. Ver Documento 8, Apéndice, en Platt et al. ([2006] 2011).

20 Cf. Margarita Menegus Bomemann (1999). Para los hitos de frontera de los incas y españoles ver Documento 15 en Platt et al. ([2006] 2011: 642).

21 Observaba Olivia Harris (1987) que los juicios en los Andes son cíclicos y no finales. La misma orden original deviene, entones, una periódica ruptura y renovación.

22 En Bolivia las prácticas vinculadas al tributo continuaron vigentes hasta después de la revolución de 1952. Comparar con: Veena Das y Deborah Poole (2004). Respecto de un proyecto de digitalizar todos los registros acerca del tributo de las comunidades indígenas en Bolivia, véase: http://www. bl.uk/about/ policies/endangeredarch/barTagan.html.

23 Runa en quechua significa "ser humano quechua hablante". El sufragio universal de los adultos fue introducido con la Revolución de 1952.

24 La historia ha estado carcomiendo los bordes de la antropología basada en el trabajo de campo más de sesenta años. A la retrospectiva de Axel (2002) habría que añadir el clarividente trabajo de R. G. Collingwood. Véase para un trabajo recién publicado de Collingwood, Boucher et al. (2005).

25 Arlette Farge (1989) describe el bautizo del neonato en esos rituales de introducción en la Biblioteca Nacional en París.

26 En la comparación que hace Lévi-Strauss de los objetos inscritos en sociedades orales con los documentos de los archivos, deberá tenerse en cuenta su explicación de la escritura como fuente de explotación en el capítulo 28 de Tristes Tropiques (1955). En La pensée sauvage argumenta que los peligros de la escritura podrían ser neutralizados, junto a la historicidad, por las simetrías del pensamiento salvaje, en cambio, en Tristes Tropiques había mostrado cuán fácilmente esta táctica colectiva puede deshacerse por intrusión y contagio de un antropólogo alfabetizado.

27 En cuanto a la oscilación de los Jívaro entre presentismo, como predación salvaje, e historia, como domesticación alienada, véase: Anne-Christine Taylor (2007).

28 En cuanto al templo andino quipu, ver: http://www.nytimes. com/2010/08/17/world/americas/17peru.html?_r=1 .

29 Respecto de la idea de historia vigente [current history] véase: Sally Falk Moore (1987).

30 Cf. Natascha Drubek-Mayer respecto de los Archivos Rusos de Cine fondo Gamil, descrito por Uzbek director Ali Khamaraev, como un "mausoleo del cine". 'Do we need Archive Film Festivals?', ARTMargins, Contemporary Centra and East European Visual Culture. Monday 31 May 2010. http.7/www.artmar- gins.com/ index.php/6-film-a-video/585-do-we-need-archive-filmfestivals-film-review-article

31 Mientras escribo este trabajo, un Report of the Widgery Tribunal (1972) relativo a los sucesos del "Domingo Sangriento" en Londonberry fue condenado como siendo una tapadera por la Saville Inquiry (2010). 
32 Véase también Gouda et al. (2009), "Debate Ann Laura Stoler".

33 Un ejemplo: Pascale Absi (2003), Les Ministres du Diable.

34 Respecto de la mina como metáfora de la investigación, véase: Platt y Quisbert (2007).

35 En cuanto al paisaje como archivo y su recomposición por medio de la memoria, siguiendo el calendario, véase: Abercrombie (1998).

36 Acerca de la pluralidad de perspectivas de las memorias, un ejemplo en el film Rashomon de Akira Kurosawa.

37 Como la memoria colectiva, y en contraste, la historia oral se negocia socialmente, ver Halbwachs, 1992.

38 Podría argumentarse que también la conciencia apenas si contiene retazos en comparación con lo que queda escondido en nuestro inconsciente. Sin embargo, la recuperación difiere tanto como es diferente un sicoanalista de un hacker. El primero tiene para extraer los infinitos recursos de un inconsciente, mientras el hacker solo puede bajar los bits de información que fueron digitalizados.

39 Charcas es la décima Audiencia Real de la Sección V (Gobierno) del Archivo, y Charcas 16 está clasificada como "Cartas y documentos del Presidente y los Jueces de la Audiencia*' (legajos 16-25), que corresponden al segundo subgrupo Secuta(legajos 16-134. año 1538-1703) del primer Grupo (legajos 1-153) de los cuatro Grupos que componen la serie Charcas (que contiene en todo 736 legajos, cada uno con un bloque de expedientes generalmente no indexados). Este primer Grupo de legajos (1-153) fue traído a Sevilla en 1786 del Archivo Estatal de Simancas fundado por Felipe II. Los papeles fueron enviados a Simancas por el Consejo de Indias en bloques sucesivos en 1603, 1658, 1681 y 1718. Ver José María de la Peña y Cámara, Guía del Archivo de Indias. Madrid, 1958. Inventario de Sección V - Gobierno, Audiencia de Charcas.

40 La burocracia sin estado de Gaza, bajo el Mandato Británico y la Administración Egipcia, gobernaban por medio de la reiteración y la autorrefetencialidad, como explica llana Feldman (2008)

41 http://vww.imec-archives.com/imec_communiques_barthes.php

42 Una versión preliminar de este trabajo fue publicado originalmente en "Between routine and rupture: the Archive as field-event.", en Sage Handbook of Social Anthropology, Vol. II, Londres (2012). 